\title{
Depressive Symptoms, Family Functioning, University Environment, and Social Support: a Population Based Study in University Students in Beijing China
}

\author{
Jing Sun ${ }^{1, *}$, Nicholas Buys ${ }^{2}$, Xinchao Wang ${ }^{3}$ \\ ${ }^{1}$ School of Public Health and Griffith Health Institute. Griffith University, Logan campus, Meadowbrook, Brisbane, O4131, Australia \\ ${ }^{2}$ School of Human Services and Social Work and Griffith Health Institute, Griffith University, Gold Coast campus, Parkland, Q4222, \\ Gold Coast, Australia \\ ${ }^{3}$ Guanghua Graduate School of Management, Peking University, Beijing, 100871, China
}

\begin{abstract}
The present study investigated the prevalence of depressive symptoms in university students from Beijing. The relationship between depression and social ecological factors in these university students was analyzed. Students from nine universities in Beijing were randomly selected to participate in the study. A total of 2046 valid responses were received from 2700 students surveyed. The General Health Questionnaire (GHQ-30) was used to measure depression. The Family Functioning Questionnaire, University Organization and Environment Scale, and Social Support Scale were used. Approximately $24.5 \%$ of students had scores on the GHQ exceeding 7.8 , whereas $63.7 \%$ reported scores of 13 or higher. Males have higher prevalence of depression than females. The following factors were associated with current depressive symptoms: (1) negative aspects of the university environment; (2) low levels of family functioning; (3) low levels of social connectedness and lack of support from family and friends.
\end{abstract}

Keywords Depression, Family Functioning, Social Support, University Environment

\section{Introduction}

Depression is now the most common mental health problem affecting university students[1]. Severe symptoms of depression in students not only lead to a lack of motivation and energy to engage in academic activities but also may put the students at risk of a wide variety of consequences, some of which can be debilitating or even fatal. In surveys of United States (US), Japanese, and Hong Kong university students, between $20.9 \%$ and $53 \%$ reported having experienced depression since beginning university [1-4] and 45\% reported feeling so depressed in the last year of university that it was difficult to function[2]. Although many surveys have been conducted to examine the prevalence of depression in university students, disparities in findings are difficult to interpret because of sampling and methodological differences.

Studies using an ecological perspective indicate that community, university, and family are important factors to determine youth mental health outcomes. From an ecological perspective[5] the influences of social context, both proximal including family, peers, and schools, and distal such as

* Corresponding author:

j.sun@griffith.edu.au (Jing Sun)

Published online at http://journal.sapub.org/ijpbs

Copyright (C) 2011 Scientific \& Academic Publishing. All Rights Reserved community, culture, and social environment are important to youth mental health. It specifies that wellbeing is affected substantially by the social contexts in which youth are embedded and is a function of the quality of relationships among individual, family, and institutional systems. Werner[6] argues that variables relating to social context are embedded in the family, the school, and the community, and these act as protective factors through modifying, ameliorating, or altering a person's response to the negative effects of risk.

Family factors are those that shape the family's ability to endure in the face of adversity and risk, and their key characteristics include warmth, affection, cohesion, commitment, and emotional support for one another[7]. These factors have also been found to be associated with mental health in youth[7]. Family-level variables center on family functioning, family coherence, and how the family as a unit copes with the stresses of life. Family coherence pertains mainly to the elements of coping, problem solving, support, communication, and understanding ${ }^{(8)}$. Resilient families generally have the resources to access support from the community, friends, and kinship networks.

A number of university-level organizational factors including a safe and supportive environment, positive peer relationships, positive teacher influences, and opportunitiesfor success have also been found to be negatively related to youth depression[9]. Such variables may have a decisive 
impact on an individual's ability to cope with stress or challenge, and are crucial in determining the extent to which a stressful situation will escalate into harm or resolve itself into adjustment and wellbeing. Thus, the presence of these protective factors in a university environment may determine a youth's ability to adjust and cope with adversity in the university. Organizational factors of importance in the university environment include its climate or ethos, the curriculum, the rules and discipline regarding the management of student behavior, expectations of the staff and parents, and opportunities for positive relationships with adult models in the university[10].

At a community level, numerous studies have indicated that social support has the ability to moderate the effects of depression[11]. Chou and Chi[11] found that social support buffered the negative impact of life stressors on depression. Brissette, Scheier and Carver[12] showed that university students who were more optimistic experienced increased community social support, which in turn led to decreased depression. Such community, friend, and kinship networks can help to give meaning to a situation, help to develop coping strategies, and, more importantly, foster the individual's ability to face challenge and change situations[13].

Despite the importance of the family, university, and community factors, there has been a lack of research on the effects of social-ecological factors on the mental health of university students in China. The present study is the first attempt to explore the prevalence rates of current depressive symptoms in university students in Beijing. It aimed to examine the association between depressive symptoms, family functioning, university environment, and community social support in university students in nine university communities with very different histories and academic rankings.

\section{Method}

\subsection{Sampling and Procedure}

Data were collected from a sample of students at nine universities in Beijing that were interested in participating in the study, using a survey questionnaire from mid-September to the end of October in 2007. Nine out of 59 eligible universities in Beijing were interested in participating in the study. Students from each of the nine universities in Beijing were randomly selected to participate in the study. Out of 2700 students invited to take part in the study, 2046 (75.8\%) completed the survey. Majority of invited students were invited from freshmen and second year students. Written informed consent was obtained from the participants. Ethical clearance to conduct the study was obtained from the human ethics committee at the Peking University.

\subsection{Measures}

Self-reported questionnaires were included in the survey instrument. These questionnaires were simplified Chinese versions of the original scales. Socio-demographic information included age, sex, place of origin, family income, and university year level. Potential confounders, such as parental marital status, education and occupation, and family monthly income, were collected in the questionnaires.

The General Health Questionnaire (GHQ-30) was used to assess depressive symptoms in university students[14]. The Chinese version of the GHQ-30 has been verified in the Chinese population[15]. This 30 -item scale was used to screen for current depressive disorder in the general population during the month of the study, with very good internal consistency[15] (Cronbach's $\alpha$ of .85 for the general population and 0.9 for the population with mental health issues). Respondents were asked to choose from four possible responses in a Likert format, where 0 is "rarely or none of the time" and 3 is "almost or all of the time (5-7 days)." Scores range from 0 to 30 , with higher scores reflecting greater levels of depressive symptoms. A score of more than 13 is suggestive of the presence of depressive symptoms, as it was strongly associated with major depression[36,37]. We delineated the level of depressive symptoms by defining three groups with GHQ-30 scores in the following ranges: less than $7.8,7.8-13$, and 14 or more.

The Family Functioning questionnaire[16] was used to measure four aspects of family functioning. This includes family coping ability, relationship among family members, family coherence, and family member communication. Four items from the Family Hardiness Index were added to the scale because hardiness has been identified as a protective factor to cope with stress at the family level. The family functioning questionnaire has 16 questions and uses a five-point Likert scale ranging from 1 = strongly disagree to $5=$ strongly agree and participants only need to select one answer among the five choices. A higher score indicates a higher level of family functioning perceived by university students. Confirmatory factor analysis indicates that the Family Functioning scale has good reliability and validity, with fit indices such as RMSEA values less than 0.08 and Comparative Fit Index (CFI) values of more than 0.94[17].

The university-level variables examined included students' perceptions of the school organizational environment, its capacity to provide good structure, clear rules and regulation, and the extent to which a supportive psychosocial environment is present in the university organization. The School Organization and Climate Scale consisted of 36 items derived from the School Organizational Health Questionnaire[18]. The items chosen from the School Organizational Health Questionnaire were modified to reflect the impressions of university students' perception about the university environment. A high score in the university environment questionnaire and subscales indicates a high level of support from university organization and environment, curricula and support system perceived by the university students. The goodness-of-fit statistics using the confirmation factor analysis approach showed the questionnaire had satisfactory reliability and validity, with the root-mean-square errors of approximation being .08 or less, the root-mean-square residuals being .05 or less, and the relative non-centrality indices being .98 or better[18]. 
The Social Support Scale consisted of 17 items from the Social Support Index[13] to assess the degree to which university students were integrated into the local community, viewed the local community as a source of support, and felt that the local community could provide emotional, self-esteem, and network support. Respondents were asked to rate each of the 17 items on a four-point scale from $1=$ strongly agree to $4=$ strongly disagree depending on how applicable each statement was to them. A higher score indicates a higher level of local community support perceived by university students. The reliabilities for individual subscales have been previously demonstrated and yielded good test-retest and internal consistency. Internal consistency was observed with $\alpha=.87[17]$.
The prevalence of depression in the nine universities was calculated according to the GHQ cut-off point of 13. An analysis of covariance was performed using the general linear model command of Statistical Package for the Social Sciences to compare the differences in family support, university environment, and community support between depressed and non-depressed university students. There was a significant difference between depressed and non-depressed group in demographic variables including age, sex, year level, family type, and university academic ranking. These factors as confounding factors were added in the subsequent statistical analysis using multivariate analysis of variance. The statistical significance level was set at a probability level less than 0.01 .

\subsection{Data Analysis}

Table 1. Depression by demographic variables $n(\%)$.

\begin{tabular}{|c|c|c|c|c|}
\hline Variable & Total & Depressed $(n=1282)$ & Non-depressed $(n=752)$ & $\chi^{2}$ \\
\hline \multicolumn{5}{|l|}{ Age group } \\
\hline $16-18$ & $347(17.1)$ & $204(59.8)$ & $137(40.2)$ & $20.21 * * *$ \\
\hline 19 & $653(32.1)$ & $404(62.2)$ & $246(37.8)$ & \\
\hline 20 & $640(31.5)$ & $383(60.0)$ & $255(40.0)$ & \\
\hline$>21$ & $393(19.3)$ & $286(73.0)$ & $106(27.0)$ & \\
\hline \multicolumn{5}{|l|}{ Sex } \\
\hline Male & $1102(54.1)$ & $728(57.0)$ & $366(49.1)$ & $11.84 * * *$ \\
\hline Female & $934(45.9)$ & $550(43.0)$ & $380(50.9)$ & \\
\hline \multicolumn{5}{|l|}{ Income group } \\
\hline$<10,000$ & $597(29.4)$ & $369(29.0)$ & $223(29.9)$ & 0.83 \\
\hline $10,000-29,999$ & $793(39.1)$ & $495(38.9)$ & $291(39.0)$ & \\
\hline $30,000-59,999$ & $382(18.8)$ & $248(19.5)$ & $134(18.0)$ & \\
\hline $60000 \&$ above & $258(12.7)$ & $160(12.6)$ & $98(13.1)$ & \\
\hline \multicolumn{5}{|l|}{ Grade } \\
\hline first year & $1205(59.1)$ & $655(51.2)$ & $541(72.5)$ & $92.20 * * *$ \\
\hline second year & $486(23.8)$ & $352(27.5)$ & $132(17.7)$ & \\
\hline third year & $262(12.9)$ & $207(16.2)$ & $54(7.2)$ & \\
\hline forth year & $85(4.2)$ & $66(5.2)$ & $19(2.5)$ & \\
\hline \multicolumn{5}{|l|}{ Family type } \\
\hline double parent & $1735(85.2)$ & $1061(83.0)$ & $664(89.0)$ & $13.42 * * *$ \\
\hline Single parent & $282(13.9)$ & $203(15.9)$ & $77(10.3)$ & \\
\hline Other & $19(0.9)$ & $14(1.1)$ & $5(0.7)$ & \\
\hline \multicolumn{5}{|l|}{ Home town } \\
\hline capital city & $490(24.1)$ & $296(23.2)$ & $194(26.0)$ & 2.39 \\
\hline big city & $283(13.9)$ & $185(14.5)$ & $98(13.1)$ & \\
\hline small city & $629(30.9)$ & $400(31.3)$ & $225(30.2)$ & \\
\hline countryside & $635(31.1)$ & $396(31.0)$ & $229(30.7)$ & \\
\hline \multicolumn{5}{|l|}{ Ranking } \\
\hline top level & $662(32.4)$ & $409(62.2)$ & $249(37.8)$ & $41.80 * * *$ \\
\hline middle level & 707 (34.6) & $389(55.3)$ & $315(44.7)$ & \\
\hline low level & $677(33.1)$ & $484(72.0)$ & $188(28.0)$ & \\
\hline
\end{tabular}

Table 2. Prevalence of depression.

\begin{tabular}{|c|c|c|c|c|}
\hline & $\begin{array}{c}\text { GHQ score 0-7.8 Not } \\
\text { depressed }(\mathrm{n}=238) \mathrm{N}(\%)\end{array}$ & $\begin{array}{c}\text { GHQ 7.9 }-13 \text { Subclinical } \\
\text { depressed }(\mathrm{n}=495) \mathrm{N}(\%)\end{array}$ & $\begin{array}{c}\text { GHQ Score }>13 \text { Clinical } \\
\text { depression }(\mathrm{n}=1282) \mathrm{N}(\%)\end{array}$ & \multirow{2}{*}{$\chi^{2}$ or F } \\
\hline Male & $118(10.9)$ & $238(22.0)$ & $728(67.2)$ & \multirow{2}{*}{$\chi^{2}=12.15^{* *}$} \\
\hline Female & $117(12.7)$ & $254(27.6)$ & $550(59.7)$ & $1278(63.7)$ \\
\hline Total & $235(11.7)$ & $492(24.5)$ & $19.7(1.4)$ & $\mathrm{F}=8.58^{* * *}$ \\
\hline
\end{tabular}

Note. ${ }^{*} \mathrm{P}<0.01 ; * * * \mathrm{P}<0.001$ 


\section{Results}

\subsection{Prevalence of Current Depressive Symptoms}

There were 2046 students included in the prevalence calculation after the exclusion of incomplete data and those not fulfilling the inclusion criteria. The mean \pm SD age of the students was $19.2 \pm 1.4$ years and the proportion of men was $54.7 \%$ (see Table 1) There were significant differences between the depressed and non-depressed groups in age, gender, grade, family type, and university ranking (see Table 1). These variables as confounding factors were later entered into the multivariate analysis of variance (MANOVA) model and their influence on the relationship between social ecological factors and depressive moods was controlled for.

As shown in Table 2, approximately $24.5 \%$ of all university students had GHQ scores between 7.8 and 13, and $63.7 \%$ reported a score of 14 or higher. There was a prevalence difference between men and women. More male students than female students were found to have depression $\left(\chi^{2}=\right.$ $12.15, \mathrm{df}=2, \mathrm{P}=0.002)$. At the GHQ cut-off point of 13 , the prevalence of depression among male students was 1.4 times higher than that among female students. Approximately $22.0 \%$ of men reported scores between 7.8 and 13 , and $67.2 \%$ reported scores of 14 or higher. However, $27.6 \%$ of women had scores of 7.8 or higher, and $59.7 \%$ reported scores of 14 or higher.

\subsection{Depressive Symptoms and Social Ecological Envi- ronment}

Students whose GHQ score was 14 or greater were defined as having current depressive symptoms. Table 4 shows depressed groups had higher GHQ scores, and perceptions of lower family support, poorer university organization and environment, and lower social support scores than those of non-depressed groups.

\subsection{Depressive Symptoms and Environmental Factors}

The data from the nine universities were combined for a MANOVA analysis to test the association of current depressive symptoms with social ecological variables.

Table 3 shows the MANOVA model including the family functioning, university environment, and community social support as independent variables. Potential confounders (age, sex, family type, and university ranking) were also entered into the model. The results show that there are significant differences between depression and non-depression groups in the perception of university environment $(\mathrm{F}=90.29, \mathrm{P}<$ $0.001)$, family functioning $(\mathrm{F}=41.33, \mathrm{P}<0.001)$, and community social support $(\mathrm{F}=37.32, \mathrm{P}<0.001)$, suggesting that university environment, family functioning, and community social support are significantly related to current depressive symptoms. Specifically, a low level of family coping, unclear school rules and regulations, student achievements that were not recognized by the university, lack of opportunity to participate in decision-making processes, low levels of support from family and friends, and feelings of being not valued and trusted by friends were all found to be related to depressive symptoms. Students who had higher university entry scores and who were in the top -ranking universities had less chance of having depressive symptoms than students in medium- and low-ranking universities.

Table 3. Comparison between depressed and non-depressed groups in university, family and community social support factors.

\begin{tabular}{|c|c|c|c|}
\hline Variable & $\begin{array}{c}\text { Depressed Mean (SD) } \\
(\mathrm{n}=1282)\end{array}$ & $\begin{array}{c}\text { Non-depressed } \\
\text { Mean (SD) }(\mathrm{n}=752)\end{array}$ & $F$ \\
\hline University environment & & & \\
\hline University ethos & $3.03(0.65)$ & $3.04(0.79)$ & 0.20 \\
\hline University rules and regulations & $2.59(0.82)$ & $3.01(0.95)$ & $62.15^{* * *}$ \\
\hline University recognize student achievements & $3.14(0.72)$ & $3.21(0.83)$ & 0.76 \\
\hline University consider student needs & $3.08(0.74)$ & $3.04(0.82)$ & 1.46 \\
\hline Staff understand students & $2.99(0.58)$ & $3.05(0.54)$ & $4.84^{*}$ \\
\hline University teaching activity & $3.04(0.80)$ & $3.13(0.73)$ & $7.22^{* *}$ \\
\hline Communication between student-staff/parents & $2.99(0.54)$ & $3.01(0.49)$ & $688.17^{* * *}$ \\
\hline University support sufficient & $3.03(0.52)$ & $3.05(0.48)$ & $30.21^{* * *}$ \\
\hline Students participate decision making & $3.06(0.82)$ & $3.14(0.78)$ & $5.09^{*}$ \\
\hline Family functioning & & & $103.30^{* * *}$ \\
\hline Family coping & $2.93(0.74)$ & $3.37(0.94)$ & $31.49^{* * *}$ \\
\hline Family relations & $3.14(0.69)$ & $3.40(0.89)$ & $51.70^{* * *}$ \\
\hline Family communicate & $2.98(0.80)$ & $3.31(0.97)$ & $11.93^{* * *}$ \\
\hline Family coherence & $3.00(0.43)$ & $3.16(0.50)$ & \\
\hline Community support & & & 80.56 \\
\hline Sense of belonging to community & $2.74(0.07)$ & $3.08(0.07)$ & $84.71^{* * *}$ \\
\hline Family friends support & $2.98(0.49)$ & $3.37(0.72)$ & $19.09^{* * *}$ \\
\hline Friends value and trust & $3.09(0.74)$ & $3.29(0.84)$ & $11.31^{* * *}$ \\
\hline Sense of security & $3.18(0.75)$ & $3.35(0.84)$ & $35.51^{* * *}$ \\
\hline Friends emotional support & $3.22(0.85)$ & $3.53(0.99)$ & \\
\hline
\end{tabular}

Notes. Gender, university ranking, family type and year level of students were controlled in the MANOVA models. Significance level: $* \mathrm{P}<0.05 ; * * \mathrm{P}<0.01 ; * * * \mathrm{P}<0.001$

Dependent variable: depression status 


\section{Discussion}

To study the nature of depression in university students, we collected a sample of Chinese university students in nine universities in Beijing. In the sample, $63.7 \%$ of university students have significant depressive symptoms according to the GHQ-30 cut-off point of 13, although it is unknown which subjects would fulfill the Diagnostic and Statistical Manual of Mental Disorders or other diagnostic criteria for major depression. A score of 14 or higher on the GHQ-30 was reported to have a $30.6 \%$ positive predictive value for the detection of true major depression[19]. Therefore, $19.5 \%$ of Beijing university students would have experienced major depression; a figure comparable to that in studies in young people and general population[20,21]. This contrasts with $3.8 \%$ of the general Mainland Chinese population experiencing such a level of depression or the $4.1 \%$ of young Chinese metropolitan population[19]. This percentage, although much higher than previously reported in young Chinese (8.3\%)[22] and young US adults (8.6\%)[23], seems to be more in line with the estimates for US university students, which are much higher than those of the general adult US population[2].

One interesting finding in this study was that the prevalence rate of current depressive symptoms among Beijing university students $(63.7 \%)$ was similar to that among US university students using the GHQ-30 cut-off point of 13 . Opposite to research in most Western countries[24], our data showed significant gender differences in the prevalence of depression in Beijing university students that prevalence of depression is higher among males than females. This pattern of difference, which has been previously found in other Chinese populations[22,25], underlines the importance of gender in investigations of university student mental health in the Chinese culture context. In the current study, female students had higher scores in the perception of school environment and organization, community support subscales, and family relations. The results suggest that male students were less interested in using social strategies such as communication and cooperation to solve problems. However, females favor such strategies as a means of self-expression, and as an avenue to obtain help with studies and adapt to the university study environment.

This finding can also be partly explained by the gender intensification hypothesis, which postulates that the physical differentiation between females and males as a result of puberty is paralleled by increasing differentiation and development of gender roles[26]. Specifically, whereas males are socialized into valuing independent exploration and competition, females are socialized into valuing interpersonal relationships. Heyman and Legare[27] also report that female adolescents are more pro-social than boys, and male adolescents are more individual and autonomous. This suggests that the lower prevalence of depression among female students may due to their better interpersonal skills acting as a protective factor, as these skills can be used to obtain support through school, community, and family relationships.

The prevalence of depression in Beijing university students compared to other regions might be explained by the psychosocial characteristics of the groups. Beijing had been under rapid social and economic development since 1990s and is therefore socially and culturally different from other regions in Mainland China. Today's university students in China encounter challenges not faced by their parents' generation due to significant social and economic changes. For example, employment of new graduates from universities and colleges, which used to be managed by the government, has become market-oriented, thus graduates now face high levels of competition for jobs. This external pressure has become a major source of stress for students as they face academic pressure arising from examination preparation and the need to acquire professional knowledge, skills, and attitudes required by employers[52]. These challenges are confronting to students who are not adaptive and resilient and could be major contributors in the etiology of depression.

In the MANOVA models, the low level of family coping and family coherence subscale was significantly related to current depression. Individuals with a low level of family coping and coherence may be prone to depression because they tend to have a low level of family support to cope with stress and challenges and poor communication among family members. Unsupportive university environments, including unclear university rules and regulations, perceptions that staff do not understand students, poor teaching quality, lack of communication among students and staff, and lack of opportunity to participate in decision making are related to occurrence of depression. This is consistent with the findings of previous research, which found that when university environment is perceived as unsupportive and alienating, it can contribute to depression by exacerbating negative affect[28]. Our findings also indicate that lack of communication among students and staff, lack of opportunity to participate in decision making, feelings of not belonging to the community, low levels of support from family and friends, and feelings of not being valued and trusted by friends were associated with depressive symptoms. Low levels of a sense of community connectedness and a lack of friend and kinship networks also enhance depressive symptoms because this decreases the opportunities to develop individual coping strategies through external supports, and, more importantly, does not help the individual face challenging situations[29]. The significant effects on depression were not changed when confounding factors including age, gender, family type, and university ranking level were simultaneously entered into the MANOVA model. This provides further evidence for the importance of the university environment, family coping, family coherence, and community social support as predictors of depression and supports Bronfenbrenner's contention that health and wellbeing are related to social and ecological factors[5]. Our results are also consistent with those of previous studies that proposed an interaction between the environmental factors and previous depression[30]. 


\section{Study Limitations}

There are several limitations to this study. First, the study was cross-sectional, and thus could not identify causal relationships between the socio-ecological variables and current depressive symptoms. Second, considering the limitations of the cross-sectional study, longitudinal studies are needed to determine the causal links between socio-ecological variables and depression, and to avoid recall bias. Third, depressive symptoms were assessed by a self-reported questionnaire rather than a structured diagnostic interview. Thus, it is not known how many students would meet the diagnostic criteria for major depressive disorder. Future research is required with participants who have gone through a proper diagnostic interview. Despite these limitations, this study is the first to explore the role of social-ecological factors in determining risk of depressive symptoms in Chinese university students.

\section{Implications of Findings}

The implications for the current study are to develop programs that strengthen students' sense of connectedness and thus their wellbeing through university. These programs might include mentoring or "buddy" schemes in which students in higher year levels play a role in assisting and supporting individual students of lower year levels, providing better orientation for students upon enrolment, and offering services to enhance their wellbeing. Further, universities need to offer high quality career and employment services to fill the gap left by the government in connecting graduates to available employment opportunities.

In recognizing the importance of family functioning in supporting students' wellbeing and mental health, universities should develop programs that enhance the university's collaboration with parents, guardians, and family members. It is necessary to ensure that universities remain cognizant of the changing roles and expectations of parents of incoming students, clarify the university's expectations of the role and responsibilities of parents and students, and determine how the university can better partner with families to support the well-being of their student family members. It is necessary to expand or improve programs and other resources, and to improve the training of staff to support the development of personal relationships between students and between students and staff members, so that they feel connected and valued in their communities.

\section{REFERENCES}

[1] Arehart-Treichel J. Mental illness on rise on college campuses Psychiatr News. 2002;37(6):6-38

[2] American University Health Association. CACA analysis of the National University Health Assessment: reference group data base. data file. BaltimoreSpring 2002

[3] Wong JG, Cheung EP, Chan KK, Ma KK, Tang SW. Web-based survey of depression, anxiety and stress in first-year tertiary education students in Hong Kong. Aust N Z J Psychiatry. 2006;40(9):777-82

[4] Yamaguchi N, Shimazaki M, Hori M, Shiraishi H. Early intervention and treatment of depressive and manic states among university students. Nippon Rinsho. 1994;52(5):1383-7

[5] Bronfenbrenner U. Ecological systems theory. Annals of Child Dev. 1989;6:187-249

[6] Werner EE. Risk resilience, and recovery: Perspectives from the Kauai Longitudinal Study. Development and Psychopathology. 1993;5:503-15

[7] Smith G. Resilience concept and findings: Implications for family therapy. J Fam Ther. 1999;21:154-8

[8] McCubbin MA, McCubbin HI, Thompson AI. Family hardiness index. In: McCubbin HI, Thompson AI, McCubbin MA, editors. Family assessment: Resiliency, coping and adaptation. Madison, Wisconsin: University of Wisconsin Publishers; 1987. p. 839

[9] Rutter M. Psychosocial resilience and protective mechanisms. Am. J. Orthopsychiat. 1987;57:316-31

[10] Baker JA, Dilly LJ, Aupperlee JL, Patil SA. The developmental context of school satisfaction: School as psychologically healthy environment. Sch Psychol Q. 2003;18(2):206-21

[11] Chou KL. Emotional autonomy and depression among Chinese adolescents. The J Genet Psychol. 2000;16(2):161-8

[12] Brissette I, Scheier MF, Carver CS. The role of optimism in social network development, coping, and psychological adjustment during a life transition. J Pers Soc Psychol. 2002;82(1):102-11

[13] McCubbin HI, Paterson J, Glynn T. Social support index. In: McCubbin HI, Thompson AI, McCubbin MA, editors. Family assessment: Resiliency, coping and adaptation: Inventories of research and practice. Madison, Wisconsin: University of Wisconsin Publishers; 1987. p. 389

[14] Goldberg D. Manual of the General Health Questionnaire. Windsor: NFER-NELSON; 1978

[15] Sun J, Stewart D, Yuan BJ, Zhang SH. Validation of General Health Questionnaire-30 in parents with primary school children. Compr Psychiat. 2011; In press

[16] Zubrick SR, Williams AA, Silburn SR, Vimpani G. Indicators of Social and Family Functioning (ISAFF Reference Instrument): Department of Family and Community Service; 2000

[17] Sun J, Stewart D. Development of population based resilience measures in the primary school setting. Health Educ. 2007;107(6):575-99

[18] Hart PM, Wearing AJ, Conn M, Carter NL, Dingle RK. Development of the school organisational health questionnaire: A measure for assessing teacher morale and school organisational climate. $\mathrm{Br} \mathrm{J}$ Educ Psychol. 2000;70(2):211-28 
[19] Lee S, Wong CK, Ungvari GS, Cheung LP, Haines CJ, Chung TKH. Screening psychiatric morbidity after miscarriage: Application of the 30-1tem General Health Questionnaire and the Edinburgh Postnatal Depression Scale. Psychosom Med. 1997;59:207-10

[20] Sawyer MG, Arney FM, Baghurst PA, Clark JJ, Graetz BW, Kosky RJ, et al. The Mental Health of Young People in Australia. Canberra: Mental Health and Special Programs Branch, Commonwealth Department of Health and Aged Care2000. Report No.: 0642446865

[21] Bland RC. Epidemiology of affective disorders: A review. Can J Psychiatry. 1997;42:367-77

[22] Lee S, Tsang A, Zhang MY. Lifetime prevalence and inter-cohort variation in DSM-IV disorders in metropolitan China. Psychol Med. 2007;37(1):61-71

[23] Jonas BS, Brody D, Roper M, Narrow WE. Prevalence of mood disorders in a national sample of young American adults. Soc Psychiatry Psychiatr Epidemiol 2003;38 (11):618-24

[24] Bitsika V, Sharpley CF, Melhem TC. Gender differences in factor scores of anxiety and depression among Australian university students: Implications for counselling interventions. Canadian Journal of Counselling. 2010;44
(1):51-64

[25] Lee S, Tsang A, Kwok K. Twelve-month prevalence, correlates, and treatment preference of adults with DSM-IV major depressive episode in Hong Kong. J Affect Disord. 2007;98(1-2):129-36

[26] Petersen AC, Sarigiani PA, Kennedy RE. Adolescent depression: Why more girls? J Youth Adolesc 1991;20:247-71

[27] Heyman GD, Legare CH. Children's beliefs about gender differences in the academic and social domains. Sex Roles. 2004;50(3/4):227-39

[28] Gutman LM, Sameroff AJ. Continuities in depression from adolescence to young adulthood: Contrasting ecological influences. Dev Psychopathol. 2004;16:967-84

[29] Rosenthal DA, Russell J, Thomson G. Social connectedness among international students at an Australian university. Soc Indic Res. 2007;84:71-82

[30] Jorm AF, Korten AE, Jacomb PA, Christensen H, Rodgers B, Pollitt P. Public beliefts about causes and risk factors for depression and schizophrenia. Soc Psychiatry Psychiatr Epidemiol. 1997;32:143-8 